\title{
Silver Release from Silver Nanoparticles in Natural Waters
}

\author{
J. Dobias and R. Bernier-Latmani* \\ École Polytechnique Fédérale de Lausanne (EPFL), CH-1015 Lausanne, Switzerland
}

Supporting Information

ABSTRACT: Silver nanoparticles (AgNPs) are used increasingly in consumer products for their antimicrobial properties. This increased use raises ecological concern because of the release of AgNPs into the environment. Once released, zero-valent silver may be oxidized to $\mathrm{Ag}^{+}$and the cation liberated or it may persist as AgNPs. The chemical form of Ag has implications for its toxicity; it is therefore crucial to characterize the persistence of AgNPs to predict their ecotoxicological potential. In this study, we evaluated the release of $\mathrm{Ag}$ from AgNPs of various sizes exposed to river and lake water for up to 4 months. Several AgNP-capping agents were also considered: polyvinylpyrrolidone (PVP), tannic acid (Tan), and citric acid (Cit). We observed a striking difference between 5 ,

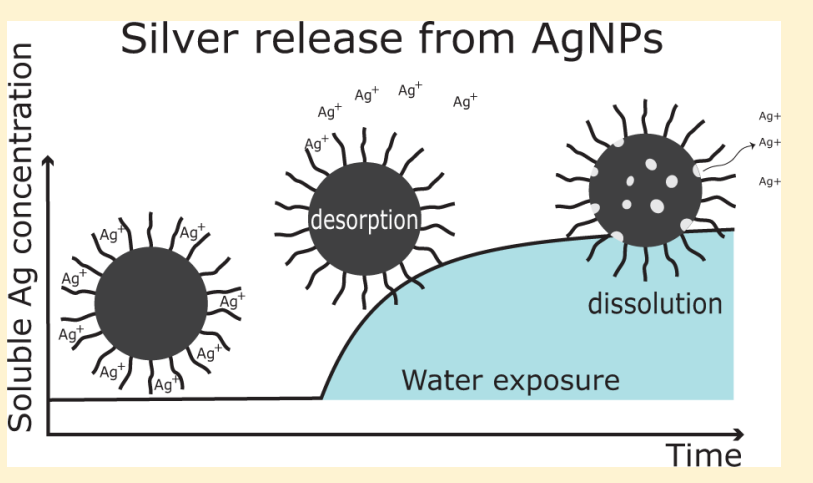
10, and $50 \mathrm{~nm}$ AgNPs, with the latter being more resistant to dissolution in oxic water on a mass basis. However, the difference decreased when Ag was surface-area-normalized, suggesting an important role of the surface area in determining $\mathrm{Ag}$ loss. We propose that rapid initial $\mathrm{Ag}^{+}$release was attributable to desorption of $\mathrm{Ag}^{+}$from nanoparticle surfaces. We also observed that PVP- and Tan-AgNPs are more prone to $\mathrm{Ag}^{+}$release than Cit-AgNPs. In addition, it is likely that oxidative dissolution also occurs but at a slower rate. This study clearly shows that small AgNPs (5 $\mathrm{nm}, \mathrm{PVP}$ and Tan) dissolve rapidly and almost completely, while larger AgNPs $(50 \mathrm{~nm})$ have the potential to persist for an extended period of time and could serve as a continuous source of $\mathrm{Ag}$ ions.

\section{INTRODUCTION}

The use of nanomaterials in consumer goods has increased significantly over the past decade to reach approximately 1300 referenced products distributed across numerous categories, including appliances, clothing, electronics, toys, housing materials, and health and fitness products. ${ }^{1,2}$ Among consumer products that include nanomaterials, nanoparticulate silvercontaining products are most numerous. ${ }^{2}$ This is because of the antimicrobial properties of silver. ${ }^{3-6}$ It has been shown that some of these consumer products release silver nanoparticles (AgNPs) in the environment during their production, useful life, ${ }^{7,8}$ or upon final disposal. ${ }^{9,10}$ Hence, there is a concern that AgNP release would adversely affect natural microbial communities, potentially causing a significant impact on aqueous ecosystems. ${ }^{9,11}$

The mechanism of AgNP toxicity to microorganisms is not well-understood. It is unclear whether AgNP toxicity is mechanistically linked to $\mathrm{Ag}^{+}$ion toxicity or whether additional nanoparticle-specific mechanisms are important. AgNPs may serve as a source of $\mathrm{Ag}^{+}$under oxic conditions through the oxidation of zero-valent $\mathrm{Ag}^{5,12,13} \mathrm{Ag}^{+}$may be released into solution or may be sorbed by the AgNPs and delivered locally at high doses to the cell (i.e., the Trojan horse effect ${ }^{14,15}$ ). $\mathrm{Ag}^{+}$ release was found to correlate to AgNP size ${ }^{13,16}$ but also to other factors, such as water chemistry or NP surface coating. ${ }^{17-22}$ Additional toxicity mechanisms include the association of AgNPs with bacterial membranes and consequent membrane damage, ${ }^{23-25}$ the intracellular uptake of
AgNPs $(<10 \mathrm{~nm}),{ }^{26}$ and the release of reactive oxygen species that induce a stress response in bacterial cells. ${ }^{27,28}$ To unravel the potential contribution of these toxicity pathways in the environment and, in particular, to evaluate whether the nonionic toxicity routes are relevant in such a context, it is essential to have a good understanding of AgNP persistence in the environment. To our knowledge, only three studies evaluated AgNP dissolution over a time course of several months. ${ }^{12,13,29}$

The first study predicts that AgNPs will not persist in an oxic solution and will undergo complete oxidative dissolution. ${ }^{12}$ Thermodynamic calculations suggest that the oxidative dissolution of AgNPs should proceed to completion under oxic conditions. ${ }^{12}$ Thus, in the absence of kinetic limitations, we would expect that AgNPs released into oxic environments would rapidly dissolve and the contaminant of concern would be $\mathrm{Ag}^{+}$ions. However, various factors, such as water chemistry or surface passivation processes, may impact the kinetics of the overall release of Ag. Hence, the rate of AgNP dissolution may be sluggish and result in the persistence of AgNPs in the environment. In contrast, the second study shows a variable extent of dissolution (1-70\% depending upon AgNP size) after 3 months under oxic aqueous conditions. ${ }^{13}$ Moreover, the authors state that surface area (SA) alone cannot explain the

Received: October 3, 2012

Revised: March 13, 2013

Accepted: March 21, 2013

Published: March 21, 2013 
dissolution of AgNPs and that the surface coatings do not affect the equilibrium solubility of AgNPs but may impact their dissolution kinetics. ${ }^{13}$ In the third study, the release of Ag from AgNPs incubated in ultrapure water was quantified over time. ${ }^{29}$ The findings clearly show that the coating [polyvinylpyrrolidone (PVP) or citrate] and the incubation temperature greatly impact the release of $\mathrm{Ag}^{+}$.

These studies provide a helpful framework to investigate the release of $\mathrm{Ag}$ from $\mathrm{AgNPs}$ in the environment because they collectively suggest that this release varies greatly depending upon nanoparticle properties and environmental parameters. Hence, these studies underscore the need to consider the complexity of the environment in its entirety by carrying out field deployments of AgNPs.

In this study, we investigated the persistence of AgNPs under environmental conditions by deploying them in a lake and two rivers for a maximum of 4 months. The effect of size and capping agent was studied by considering AgNPs of 5, 10, and $50 \mathrm{~nm}$ coated with PVP, tannic acid (Tan), or citric acid (Cit). Complementary laboratory experiments were carried out to support conclusions from field observations.

\section{MATERIALS AND METHODS}

Preparation of Nanoparticles for Deployment. Spherical silver nanoparticles of various sizes and surface coatings were considered in this study: 5 and $50 \mathrm{~nm}$ PVP-coated AgNPs $(6.5 \pm 0.8$ and $53.4 \pm 5.0 \mathrm{~nm}), 5$ and $50 \mathrm{~nm}$ Tan-coated AgNPs $(4.3 \pm 1.3$ and $52.1 \pm 7.1 \mathrm{~nm})$, and 10 and $50 \mathrm{~nm}$ Citcoated AgNPs $(8.2 \pm 1.2$ and $49.1 \pm 4.5 \mathrm{~nm})$ were obtained from nanoComposix (San Diego, CA) as suspensions in water $(20 \mathrm{mg} / \mathrm{L})$ and characterized by transmission electron microscopy (TEM) and dynamic light scattering (DLS) (see Figures S1 and S2 of the Supporting Information). To expose AgNPs to natural waters and to quantify silver loss overtime, we embedded the nanoparticles in 4\% low-melt agarose (Applichem GmbH, Darmstadt, Germany) at a concentration of $1000 \mu \mathrm{g} / \mathrm{L}$ by gently stirring a mixture of melted gel and AgNPs and aspirating the mixture into polyvinyl chloride (PVC) tubing ( $3 \mathrm{~mm}$ inner diameter) with a syringe. The tubing was then placed on ice to accelerate gelation, pushed out of the tube with a flow of $\mathrm{N}_{2}$, cut into $3.5 \mathrm{~cm}$ long pieces, and placed into individual deployment tubes. Because the gel puck preparation requires melting the agarose at $60{ }^{\circ} \mathrm{C}$, a control experiment was carried out to ascertain the effect of the temperature, and no additional silver release was measured due to the preparation step (see S1 of the Supporting Information). ${ }^{30-32}$

The deployment tubes consisted of $1.5 \mathrm{~mL}$ polypropylene microcentrifuge screw cap tubes into the side of which six slits $(2 \times 45 \mathrm{~mm})$ were cut lengthwise (Figure S3 of the Supporting Information). The tubes were placed in holders made of two polypropylene square plates $(10 \times 10 \times 1.2 \mathrm{~cm})$, equipped with 12 depressions $(10 \times 6 \mathrm{~mm}$ for the upper plate and $8 \times 6 \mathrm{~mm}$ for the lower plate) equidistant from the plate center, and held together with cable ties (Figure S3 of the Supporting Information). For river deployment, the holders were attached to galvanized steel poles $(3.5 \times 180 \mathrm{~cm})$ with nylon wires. The poles were hammered down into the riverbed to a depth of about $50 \mathrm{~cm}$ (Figure S4A of the Supporting Information). For lake deployment, the holders were attached to a cable (Figure S4B of the Supporting Information) at about $100 \mathrm{~m}$ below the water surface. Individual gel puck weights were recorded before and after deployment. Diffusion limitations within the gel pucks exist, and it is estimated that solutes and water diffuse through the gel on the order of hours. ${ }^{30-32}$

Deployment Sites. The selected sites are located in Switzerland at the following coordinates (latitude, longitude, and elevation): NG1 (46.494463, 6.579595, and 372), R1 (46.504598, 6.430565, and 455), R2 (46.549241, 6.541399, and 395). NG1 is located in Lake Geneva; R1 is a small river (Le Boiron); and R2 a midsize river (La Venoge), both located in the region of Morges, Vaud. The two rivers are protected from direct sunlight exposure because they run through a shady forest. Physicochemical characteristics of the waters are presented in Figures S5 and S6 of the Supporting Information.

Sample Retrieval and Processing. The samples were deployed between October and March, covering Western European fall and winter seasons. The lake samples were retrieved after 1 and 4 months, and the river samples were retrieved after 2 weeks and 1 month for R1 and 2 weeks, 1 month, and 4 months for R2. Water samples were collected for chemical analysis at deployment and retrieval times. Retrieved gel pucks were placed in epitubes, weighed, dried at $60{ }^{\circ} \mathrm{C}$ for at least 2 days, and weighed again. A total of $1 \mathrm{~mL}$ of nitric acid (12\%) was added to the dry gel pucks, and the mixture was incubated for at least 3 days to dissolve the remaining AgNPs. The loss of silver was determined by comparing the mass of silver normalized to dry gel puck weight before and after deployment.

Laboratory Experiments. Laboratory experiments were used to test hypotheses generated by the field experiments. Gel pucks were prepared as described above. Water from river R1 was collected and filtered through a $3 \mu \mathrm{m}$ and then a $0.22 \mu \mathrm{m}$ pore size filter (GSWP $47 \mathrm{~mm}$, Merck Millipore, Billerica, MA). Serum bottles were amended with $200 \mathrm{~mL}$ of water. For anoxic conditions, water in the bottles was bubbled with $\mathrm{N}_{2}$ for $2 \mathrm{~h}$ and incubated overnight in an anoxic glovebox. The next day, the measured dissolved oxygen (DO) concentration was $0.09 \pm$ $0.05 \mathrm{mg} / \mathrm{L}$.

All of the bottles were sealed and cooled to and maintained at $10{ }^{\circ} \mathrm{C}$ (river water temperature) in an ice water bath. Several gel pucks or a control $\mathrm{AgNO}_{3}$ solution was added to the bottles and incubated under either oxic or anoxic conditions. At 5, 30, and $60 \mathrm{~min}$, a water sample was retrieved for ultracentrifugation (see below) and the gel pucks were collected from the corresponding bottle. The aqueous concentration of $\mathrm{Ag}$ was taken to represent released $\mathrm{Ag}$, and the gel puck analysis postdeployment allowed for the evaluation of Ag loss (as described for field deployment). The remaining solution was acidified with $\mathrm{HNO}_{3}(0.5 \%$ final concentration $)$ to desorb $\mathrm{Ag}$ from the walls and analyzed for $\mathrm{Ag}$ content. A mass balance was calculated, and $\geq 90 \%$ of $\mathrm{Ag}$ was accounted for.

Ultracentrifugation was carried out to differentiate between AgNPs (pellet) and solution silver (supernatant). It was performed using a Beckman Coulter LX80P system with a swinging bucket rotor SW60-TI at $60000 \mathrm{rpm}$ [485000 relative centrifugal force (RCF)] for $2 \mathrm{~h}$ at $20^{\circ} \mathrm{C}$. Centrifuge tubes were tested for $\mathrm{Ag}$ sorption by amending filtered river water or $18 \mathrm{M} \Omega \cdot \mathrm{cm} \mathrm{H} \mathrm{H}_{2} \mathrm{O}$ with silver nitrate $(1.8 \mu \mathrm{g} / \mathrm{L})$ and incubating for $3 \mathrm{~h}$. No sorption was observed.

The effect of $\mathrm{NaCl}$ on the release of $\mathrm{Ag}$ from AgNPs was evaluated by measuring $\mathrm{Ag}$ release from gel pucks containing AgNPs into R1 water either unaltered or amended with $25 \mathrm{mg} /$ $\mathrm{L} \mathrm{NaCl}$ to represent $\mathrm{R} 2$ water. The incubations were sampled after 5 min, 1 day, 1 week, and 2 weeks. 


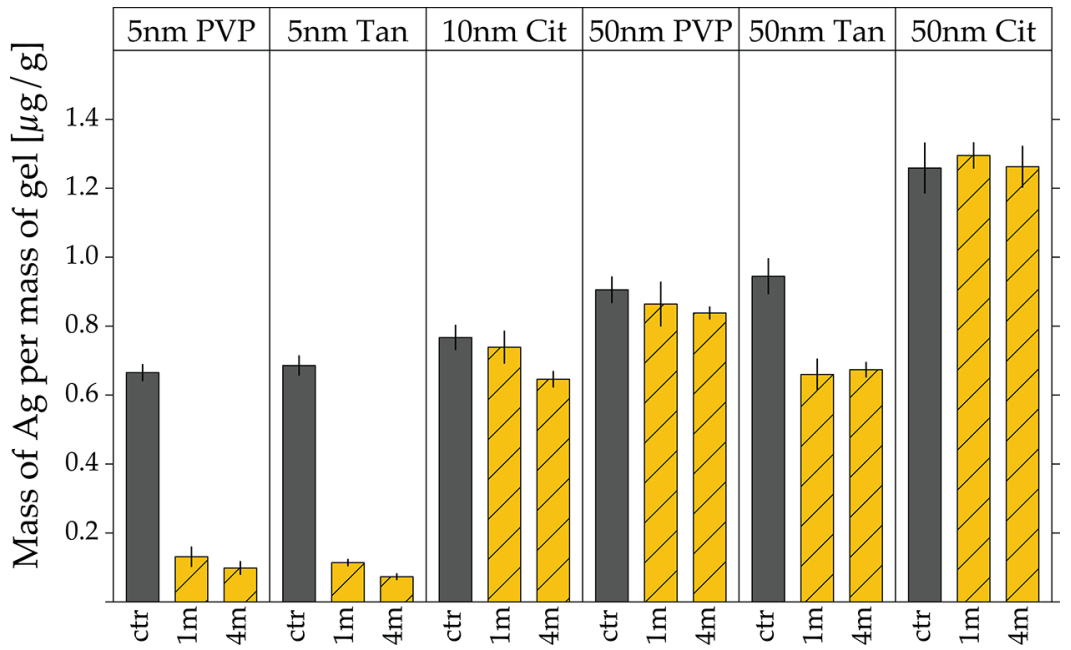

Figure 1. Silver content of gel pucks (in micrograms of Ag per gram of dry gel) deployed in Lake Geneva for 1 and 4 months (hatched bars, 1 and 4 months). The first bar in each panel represents the undeployed gel pucks [control (ctr)]. Error bars represent the range of measurements for duplicate deployed gel pucks and five undeployed gel pucks.

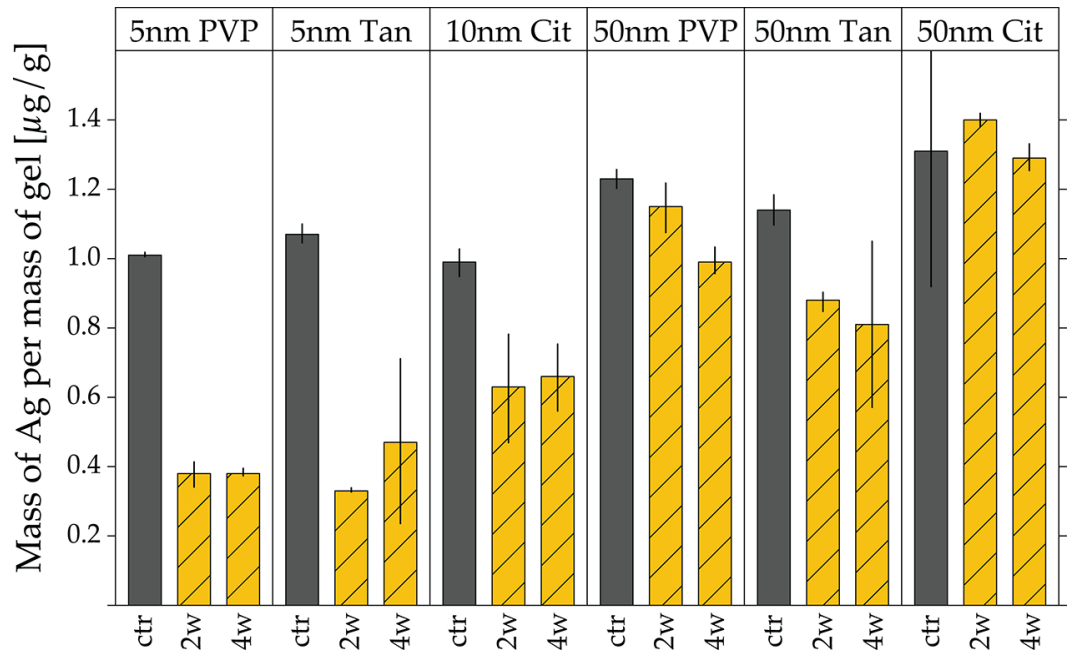

Figure 2. Silver content of gel pucks (in micrograms of Ag per gram of dry gel) deployed in R1 river for 2 and 4 weeks (hatched bars, 2 and 4 weeks). The first bar in each panel represents the undeployed gel pucks (ctr). Error bars represent the range of measurements for duplicate deployed gel pucks and five undeployed gel pucks.

Analytical Approaches. Total organic carbon (TOC) in water was measured on a Shimadzu total organic carbon analyzer TOC-V CPH coupled to an autosampler ASI-V. Anions and cations in water were measured by ion chromatography (DX-3000, Dionex, Sunnyvale, CA) with an IonPac AS11-HC column. Elution was carried out using a gradient of $0.5-30 \mathrm{mM} \mathrm{KOH}$. Ag solution concentrations originating from the gel pucks digestion were determined using inductively coupled plasma-optical emission spectroscopy (ICP-OES, Shimadzu ICPE 9000), and the samples and standards were prepared in $1.2 \% \mathrm{HNO}_{3}$ (final concentration).

$\mathrm{Ag}$ solution concentrations in aqueous samples were measured using inductively coupled plasma-mass spectrometry (ICP-MS, Perkin-Elmer DRCII) with a detection limit of 0.09 ppt for silver. Samples and standards were prepared in $0.5 \%$ $\mathrm{HNO}_{3}$ (final concentration). Dissolved oxygen (DO), $\mathrm{pH}$, and temperature were measured on site with a portable meter HQ40d (Hack Company, Loveland, CO) with $\mathrm{pH}$ (PHC101) and DO (LDO101) probes that included integrated temperature probes.

\section{RESULTS AND DISCUSSION}

In situ deployment of AgNPs presents a significant advantage over laboratory studies in that it captures the natural variability of the aqueous environment over time and, hence, is taken to be representative of environmental processes.

Figures 1-3 provide results showing silver lost from deployed gel pucks for all AgNPs among the three chosen sites (lake, R1, and R2). Several trends are observed: (a) small $(5 \mathrm{~nm})$ nanoparticles release more $\mathrm{Ag}$ (normalized to mass of gel) than large $(50 \mathrm{~nm})$ nanoparticles; (b) the largest amount of silver loss occurs primarily between deployment and the first time point; (c) in the lake and R2, there is sustained loss of Ag from 5 to $10 \mathrm{~nm}$ AgNPs and in R1 from $50 \mathrm{~nm}$ AgNPs after the first time point; and (d) initial Ag loss is more prevalent for Tan- and PVP-coated AgNPs than Cit-coated AgNPs. We considered each of these observations to extract conclusions about the behavior of AgNPs in natural waters.

Size-Dependent Release of Ag. Loss of $\mathrm{Ag}$ is clearly related to AgNP size when the data are presented as a function of the mass loss. At all three deployment sites (Figures 1-3), 5 


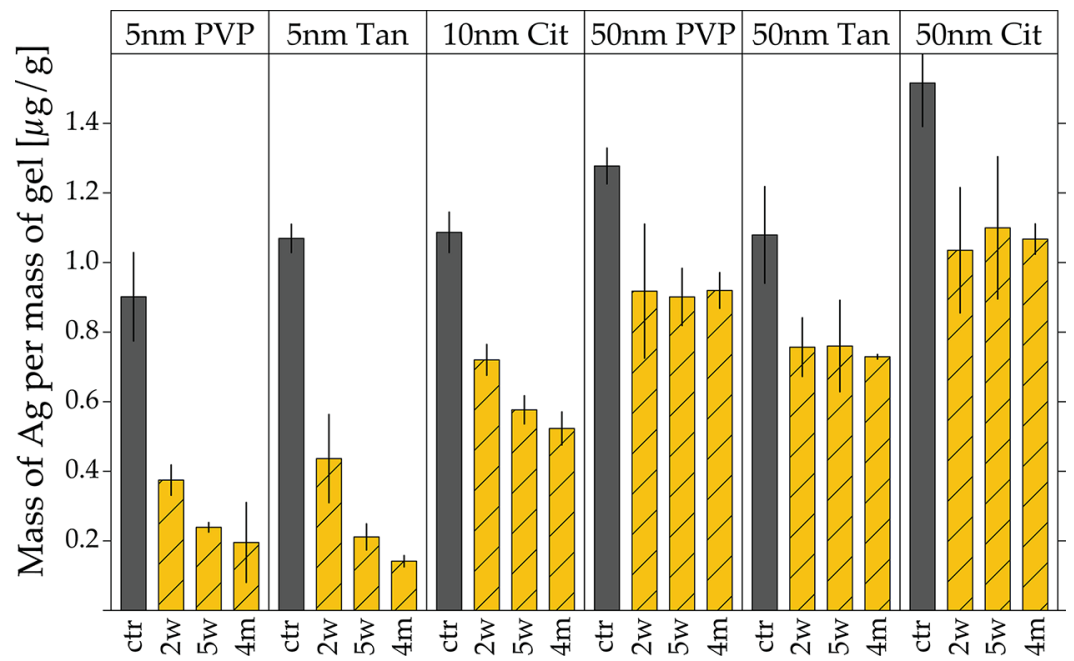

Figure 3. Silver content of gel pucks (in micrograms of Ag per gram of dry gel) deployed in R2 river for 2 weeks, 5 weeks, and 4 months (hatched bars, 2 weeks, 5 weeks, and 4 months). The first bar in each panel represents the undeployed gel pucks (ctr). Error bars represent the range of measurements for duplicate deployed gel pucks and five undeployed gel pucks.
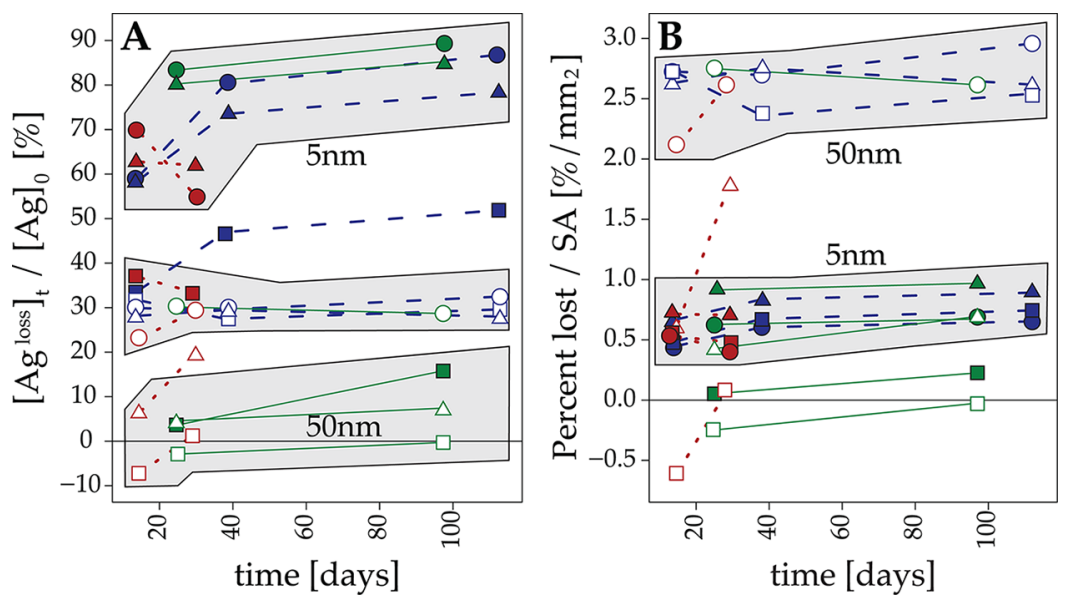

Figure 4. Time-resolved silver loss in (A) percent and (B) percent per SA from lake (plain lines), R1 river (dotted lines), and R2 river (dashed lines) deployments. $\left[\mathrm{Ag}^{\text {loss }}\right]_{\mathrm{t}} \mathrm{Ag}$ loss from gel in micrograms of $\mathrm{Ag}$ per gram of gel; $[\mathrm{Ag}]_{0}$, initial concentration of silver in gel in micrograms of $\mathrm{Ag}$ per gram of gel; and SA, surface area per gram of gel in millimeter squared per gram of gel. Legends: PVP $(\boldsymbol{\Lambda}, 5 \mathrm{~nm} ; \triangle, 50 \mathrm{~nm})$, Tan $(\bullet, 5 \mathrm{~nm}$; O, 50 $\mathrm{nm})$, and Cit $(\boldsymbol{\square}, 10 \mathrm{~nm} ; \square, 50 \mathrm{~nm})$. Shaded regions correspond to clusters of data for 5 or $50 \mathrm{~nm}$ AgNPs.

nm AgNPs display significantly more loss (85-89\%) than 50 $\mathrm{nm}$ AgNPs over the same time frame. A similar size dependency, where the mass-normalized dissolution rate is greater for small AgNPs, was observed previously when the dissolution of citrate-coated AgNPs was studied in the presence of the oxidant $\mathrm{H}_{2} \mathrm{O}_{2}{ }^{33}$ However, if the process was surfacecontrolled, we would expect similar loss regardless of size when the data are normalized to SA. We compared mass-based percent silver loss (Figure 4A) and silver loss normalized to SA for all cases (Figure 4B).

We observed a permutation of the order of mass-based and SA-normalized Ag loss for 5 and $50 \mathrm{~nm}$ AgNPs. For the smaller nanoparticles, SA normalization results in Ag loss that is smaller than that for $50 \mathrm{~nm}$ AgNPs. Additionally, there is approximately a 7-fold difference between small and large AgNPs in the SAnormalized Ag loss, whereas there is a 2 orders of magnitude difference in SA between the 5 and $50 \mathrm{~nm}$ AgNPs. This finding suggests a dominant effect of SA in determining Ag loss and confirms findings by other studies. ${ }^{34}$ The permutation in the order of maximum $\mathrm{Ag}$ release as compared to the expected order (smaller particles release more) suggests that other unidentified factors could also play a role.

The $5 \mathrm{~nm}$ and $50 \mathrm{~nm}$ AgNPs respectively cluster in the SAnormalized plot regardless of the coating (except for citrate; see below) and deployment site (Figure 4B), suggesting that size (in addition to SA, as stated above) also impacts Ag release. The Cit-coated AgNPs were the only exception to this trend (Figure 4B). Hence, it appears that this type of surface coating may contribute to modulating Ag loss from the AgNPs.

Mechanism of Release of Ag. In most cases, we observed a rapid loss of $\mathrm{Ag}$ at the first time point after deployment, which suggests a rapid initial loss rate (Figures 1-3). We explored two hypotheses to account for that initial loss: (1) an oxidative dissolution process with $\mathrm{O}_{2}$ as the oxidant as described by Liu et al. ${ }^{12}$ or (2) the release of chemisorbed $\mathrm{Ag}^{+}$as described by Lok et al. ${ }^{5}$

The first hypothesis was explored by carrying out $\mathrm{Ag}$ release experiments with gel pucks embedded with 5 and $50 \mathrm{~nm}$ PVPcoated AgNPs in oxic or anoxic $0.22 \mu \mathrm{m}$ prefiltered R1 water. After $5 \mathrm{~min}$ of exposure, approximately $30 \%$ of $\mathrm{Ag}$ is lost from 5 
$\mathrm{nm}$ AgNP gel pucks regardless of the oxygen content of the solution (Figure 5). The similarity in Ag release between oxic

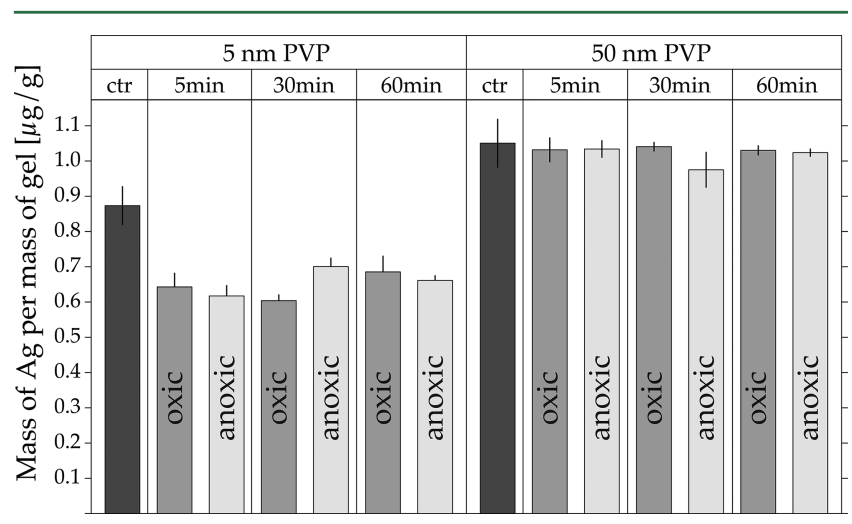

Figure 5. Mass of silver $(\mu \mathrm{g})$ per gram of gel remaining in gel pucks loaded with 5 and $50 \mathrm{~nm}$ PVP-coated AgNPs after exposure to oxic and anoxic filtered R1 water for 5, 30, and $60 \mathrm{~min}$ and unexposed to filtered water (ctr). Error bars represent the standard deviation for five gel pucks.

and anoxic conditions suggests that oxidative dissolution cannot explain this rapid initial silver release. A more likely explanation is the release of sorbed $\mathrm{Ag}^{+}$from the surface of the AgNPs.

In the case of $50 \mathrm{~nm}$ AgNPs, consistent with results from the field deployment, no significant Ag loss and no effect of oxic/ anoxic conditions was observed. Hence, we conclude that oxidative dissolution likely plays a minor role in the initial release of $\mathrm{Ag}$ from the AgNPs deployed in the field. A calculation of the fraction of sorbed $\mathrm{Ag}$ that is released upon exposure to water yields 2 and $6 \%$ for 5 and $50 \mathrm{~nm} \mathrm{AgNPs,}$ respectively (see Table $S 1$ of the Supporting Information). Thus, it is realistic to consider that the released Ag was initially present as sorbed Ag.

Nonetheless, we cannot exclude the possibility that, in addition to the rapid release of sorbed $\mathrm{Ag}^{+}$, a slower process of oxidative dissolution takes place. The sustained release of $\mathrm{Ag}$ after the first time point, which is observed for 5 and $10 \mathrm{~nm}$ PVP-, Tan-, and Cit-coated AgNPs (Figure 1), $50 \mathrm{~nm}$ PVP- and Tan-coated AgNPs (Figure 2), and $5 \mathrm{~nm}$ PVP-, $5 \mathrm{~nm}$ Tan-, and $10 \mathrm{~nm}$ Cit-coated AgNPs (Figure 3), is consistent with a slow oxidative dissolution step.

Previous studies ${ }^{12}$ have shown a large difference in $\mathrm{Ag}$ release under oxic and anoxic conditions. We attribute the different outcome of our findings to the specific solution chemistry in our study. Desorption may be predominant in our study because the rate of oxidative dissolution is very slow because of the $\mathrm{pH}$ values of lake and river water (7.9-8.4). It has been shown ${ }^{12}$ that the rate of release of Ag from AgNPs decreases rapidly at $\mathrm{pH}$ values $\geq 8$. In contrast, the study showing extensive oxidative dissolution ${ }^{12}$ under oxic conditions was carried out at a $\mathrm{pH}$ value of $5.68, \mathrm{pH}$ at which oxidative dissolution is approximately 3 -fold faster than at $\mathrm{pH} 8$.

To test the second hypothesis and to exclude the possibility of physical release of AgNPs from the gel, we exposed gel pucks to $0.22 \mu \mathrm{m}$ prefiltered $\mathrm{R} 1$ water for 5 or $60 \mathrm{~min}$. At each time point, water was collected and ultracentrifuged at $485000 \mathrm{RCF}$ for $2 \mathrm{~h}$ and the supernatant fraction was analyzed for silver content by ICP-MS. A control experiment indicated that $5 \mathrm{~nm}$ PVP-coated AgNPs were localized in the pellet under these conditions. At both time points, there was no measurable difference in the concentration before and after ultra- centrifugation, indicating that silver is in a soluble form (Figure 6). Hence, the rapid release of $\mathrm{Ag}$ from the AgNPs cannot be

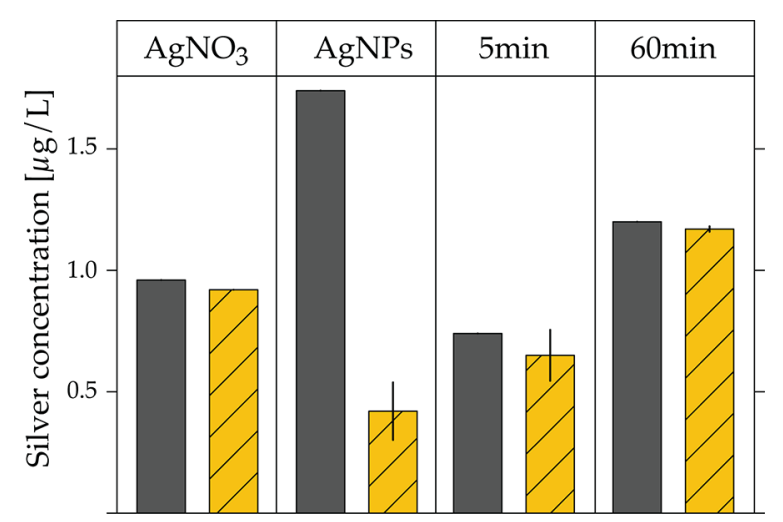

Figure 6. Concentration of silver in solutions amended with $\mathrm{AgNO}_{3}$ $\left(\mathrm{AgNO}_{3}\right), 5 \mathrm{~nm}$ PVP-AgNPs (AgNP), or incubated for 5 or $60 \mathrm{~min}$ with gel pucks containing $5 \mathrm{~nm}$ PVP-AgNPs (5 and $60 \mathrm{~min}$ ). The silver concentration was measured prior to (plain bar) and after (hatched bar) ultracentrifugation. Error bars on the yellow bars represent replicate ultracentrifugation runs.

attributed to an experimental artifact of physical loss of AgNPs from the gel but rather is likely due to the release of sorbed $\mathrm{Ag}^{+}$ species from the surface of $\mathrm{Ag}$ nanoparticles. The presence of chemisorbed $\mathrm{Ag}^{+}$at the surface of AgNPs under oxic conditions is well-documented, ${ }^{5,35}$ and the desorption of $\mathrm{Ag}^{+}$upon incubation of these AgNPs in Ag-free oxic or anoxic aqueous solution is expected as a result of mass action.

Anoxic modifications of AgNPs, such as sulfidation, were not considered because the systems studied are fully oxic.

Role of the Aqueous Chemical Composition in Ag Release. When comparing the two river sites, we note that $\mathrm{R} 2$ displays the sustained loss of Ag beyond the first time point for the smaller ( 5 and $10 \mathrm{~nm}$ ) AgNPs but that R1 does not. We hypothesize that oxidative dissolution is more rapid in $\mathrm{R} 2$ than in $\mathrm{R} 1$ and that differences in the chemical composition of the two river waters account for this disparity in behavior. To evaluate this hypothesis, we compared the major ion content of both waters (see Figure S4 of the Supporting Information) and found that sodium and chloride were present in higher concentrations in R2 water. We chose to evaluate the potential impact of sodium chloride on oxidative dissolution by comparing the release of Ag from PVP-coated AgNPs embedded in gel pucks incubated in $\mathrm{R} 1$ water to those incubated in $\mathrm{R} 1$ water amended with $25 \mathrm{mg} / \mathrm{L} \mathrm{NaCl}$ at $10{ }^{\circ} \mathrm{C}$. Overall, we observe little to no difference between the two systems (see Figure S7 of the Supporting Information), suggesting factors other than $\mathrm{NaCl}$ content (e.g., TOC content and speciation) as being important in explaining field differences between $\mathrm{R} 1$ and $\mathrm{R} 2$.

Role of AgNP Coating on Ag Release. The final observation gleaned from the field deployment is that there are significant differences in $\mathrm{Ag}$ release from AgNPs depending upon the surface coating. Notably, a Cit coating leads to lower initial Ag loss compared to a PVP or Tan coating (Figures 1-3). Similar observations have emerged from several studies. A comparison of Cit- and PVP-coated AgNPs showed that PVP-coated AgNPs $(8 \mathrm{~nm})$ released almost an order of magnitude higher Ag concentration than citrate-coated AgNPs of comparable size $(7 \mathrm{~nm}))^{36}$ There appears to be several 
mechanisms by which the surface coating impacts AgNP dissolution. In the case of citrate, $\mathrm{Ag}^{+}$binding to the carboxylic groups of the organic acid has been proposed ${ }^{12}$ as a process that leads to the retention of $\mathrm{Ag}^{+}$, hence lowering solubility. Additionally, citrate may act as a reducing agent at the AgNP surface, reducing the oxide layer back to zero-valent $\mathrm{Ag}$ and decreasing solubility. ${ }^{37}$ It should be noted, however, that no clear trend in the effect of surface coating on oxidative dissolution was detected in this study.

Environmental Implications. The present work focuses on observing the release of $\mathrm{Ag}^{+}$from AgNPs in natural waters under field conditions. Although more than $80 \%$ of loss was documented for small AgNPs $(<10 \mathrm{~nm})$, complete dissolution was never observed, confirming previous observations. ${ }^{29}$ Larger AgNPs $(50 \mathrm{~nm})$ lost no more than $50 \%$ of the initial silver content after 4 months, with most of the loss being attributable to $\mathrm{Ag}^{+}$desorption. These results suggest that the initial and dominant silver release process was desorption of chemisorbed $\mathrm{Ag}^{+}$from the surface of AgNPs. Oxidative dissolution also likely plays a role but is a much slower process under these conditions.

Overall, AgNPs were shown to have the potential to persist in the environment for extended periods of time. The results from this study suggest that AgNPs should continue to be studied as nanomaterials in the environment because they will be present in that form at least for the medium term. Hence, research aiming at differentiating between AgNP- and $\mathrm{Ag}^{+}$mediated toxicity mechanisms remains very important.

\section{ASSOCIATED CONTENT}

\section{S Supporting Information}

Details of the temperature control experiment, TEM micrograph, and DLS measurements of AgNPs used in this study, deployment sites and materials, IC water composition, measurements of water $\mathrm{DO}, \mathrm{pH}$, and temperature, calculation of the silver ion fraction released, and time-scale experiment testing the effect of $\mathrm{NaCl}$. This material is available free of charge via the Internet at http://pubs.acs.org.

\section{AUTHOR INFORMATION}

\section{Corresponding Author}

*Telephone: +41-21-693-50-01. Fax: +41-21-693-62-05. Email: rizlan.bernier-latmani@epfl.ch.

\section{Notes}

The authors declare no competing financial interest.

\section{ACKNOWLEDGMENTS}

We thank Jean-Luc Loizeau and Neil Graham from Institute Cipel in Versoix for their help in lake deployments and Daniel S. Alessi and Leia Falquet for their help on deploying and retrieving samples in the rivers. Also, we are grateful to the "Inspection de la Pêche du Canton de Vaud" for allowing the deployment of AgNPs. Furthermore, we thank Ruud Hovius from Horst Vogel's Laboratory (LCPPM EPFL) for providing us with ultracentrifugation help and materials. Finally, we are grateful to three anonymous reviewers for their constructive impact on this manuscript.

\section{REFERENCES}

(1) Luoma, S. N. Silver Nanotechnologies and the Environment: Old Problems or New Challenges; Project on Emerging Nanotechnologies Inventory, Woodrow Wilson International Center for Scholars:
Washington, D.C.; http://www.nanotechproject.org/publications/ archive/silver/.

(2) Project on Emerging Nanotechnologies Inventory, Woodrow Wilson International Center for Scholars. http://www. nanotechproject.org/inventories/consumer/analysis_draft/.

(3) Sotiriou, G. A.; Pratsinis, S. E. Antibacterial activity of nanosilver ions and particles. Environ. Sci. Technol. 2010, 44 (14), 5649-5654.

(4) Sharma, V. K.; Yngard, R. A.; Lin, Y. Silver nanoparticles: Green synthesis and their antimicrobial activities. Adv. Colloid Interface Sci. 2009, 145 (1-2), 83-96.

(5) Lok, C. N.; Ho, C. M.; Chen, R.; He, Q. Y.; Yu, W. Y.; Sun, H.; Tam, P. K. H.; Chiu, J. F.; Che, C. M. Silver nanoparticles: Partial oxidation and antibacterial activities. J. Biol. Inorg. Chem. 2007, 12 (4), $527-534$.

(6) Marambio-Jones, C.; Hoek, E. A review of the antibacterial effects of silver nanomaterials and potential implications for human health and the environment. J. Nanopart. Res. 2010, 12 (5), 1531-1551.

(7) Benn, T. M.; Westerhoff, P. Nanoparticle silver released into water from commercially available sock fabrics. Environ. Sci. Technol. 2008, 42 (11), 4133-4139.

(8) Durán, N.; Marcato, P.; Alves, O.; Da Silva, J.; De Souza, G.; Rodrigues, F.; Esposito, E. Ecosystem protection by effluent bioremediation: Silver nanoparticles impregnation in a textile fabrics process. J. Nanopart. Res. 2010, 12 (1), 285-292.

(9) Gottschalk, F.; Nowack, B. The release of engineered nanomaterials to the environment. J. Environ. Monit. 2011, 13 (5), $1145-1155$.

(10) Kim, B.; Park, C. S.; Murayama, M.; Hochella, M. F. Discovery and characterization of silver sulfide nanoparticles in final sewage sludge products. Environ. Sci. Technol. 2010, 44 (19), 7509-7514.

(11) Blaser, S. A.; Scheringer, M.; MacLeod, M.; Hungerbühler, K. Estimation of cumulative aquatic exposure and risk due to silver: Contribution of nano-functionalized plastics and textiles. Sci. Total Environ. 2008, 390 (2-3), 396-409.

(12) Liu, J. Y.; Hurt, R. H. Ion release kinetics and particle persistence in aqueous nano-silver colloids. Environ. Sci. Technol. 2010, 44 (6), 2169-2175.

(13) Ma, R.; Levard, C.; Marinakos, S. M.; Cheng, Y. W.; Liu, J.; Michel, F. M.; Brown, G. E.; Lowry, G. V. Size-controlled dissolution of organic-coated silver nanoparticles. Environ. Sci. Technol. 2012, 46 (2), $752-759$.

(14) Lubick, N. Nanosilver toxicity: Ions, nanoparticles-or both? Environ. Sci. Technol. 2008, 42 (23), 8617-8617.

(15) Park, E. J.; Yi, J.; Kim, Y.; Choi, K.; Park, K. Silver nanoparticles induce cytotoxicity by a Trojan-horse type mechanism. Toxicol. In Vitro 2010, 24 (3), 872-878.

(16) Zhang, W.; Yao, Y.; Sullivan, N.; Chen, Y. S. Modeling the primary size effects of citrate-coated silver nanoparticles on their ion release kinetics. Environ. Sci. Technol. 2011, 45 (10), 4422-4428.

(17) Fabrega, J.; Renshaw, J. C.; Lead, J. R. Silver nanoparticles in natural waters: Behaviour and impact on bacterial communities. Water-How Need Drives Research and Research Underpins Solutions to World-Wide Problems; University of Birmingham, Birmingham, U.K., July 20-25, 2008; pp 1-3.

(18) Navarro, E.; Piccapietra, F.; Wagner, B.; Marconi, F.; Kaegi, R.; Odzak, N.; Sigg, L.; Behra, R. Toxicity of silver nanoparticles to Chlamydomonas reinhardtii. Environ. Sci. Technol. 2008, 42 (23), 8959-8964.

(19) Neal, A. L. What can be inferred from bacterium-nanoparticle interactions about the potential consequences of environmental exposure to nanoparticles? Ecotoxicology 2008, 17 (5), 362-371.

(20) Cumberland, S. A.; Lead, J. R. Particle size distributions of silver nanoparticles at environmentally relevant conditions. J. Chromatogr., A 2009, 1216 (52), 9099-9105.

(21) Fabrega, J.; Fawcett, S. R.; Renshaw, J. C.; Lead, J. R. Silver nanoparticle impact on bacterial growth: Effect of $\mathrm{pH}$, concentration, and organic matter. Environ. Sci. Technol. 2009, 43 (19), 7285-7290.

(22) Gao, J.; Youn, S.; Hovsepyan, A.; Llaneza, V. L.; Wang, Y.; Bitton, G.; Bonzongo, J.-C. J. Dispersion and toxicity of selected 
manufactured nanomaterials in natural river water samples: Effects of water chemical composition. Environ. Sci. Technol. 2009, 43 (9), $3322-3328$.

(23) Dror-Ehre, A.; Mamane, H.; Belenkova, T.; Markovich, G.; Adin, A. Silver nanoparticle-E. coli colloidal interaction in water and effect on E. coli survival. J. Colloid Interface Sci. 2009, 339 (2), 521526.

(24) El Badawy, A. M.; Silva, R. G.; Morris, B.; Scheckel, K. G.; Suidan, M. T.; Tolaymat, T. M. Surface charge-dependent toxicity of silver nanoparticles. Environ. Sci. Technol. 2011, 45 (1), 283-287.

(25) Fabrega, J.; Renshaw, J. C.; Lead, J. R. Interactions of silver nanoparticles with Pseudomonas putida biofilms. Environ. Sci. Technol. 2009, 43 (23), 9004-9009.

(26) Morones, J. R.; Elechiguerra, J. L.; Camacho, A.; Holt, K.; Kouri, J. B.; Ramirez, J. T.; Yacaman, M. J. The bactericidal effect of silver nanoparticles. Nanotechnology 2005, 16 (10), 2346-2353.

(27) Choi, O.; Hu, Z. Size dependent and reactive oxygen species related nanosilver toxicity to nitrifying bacteria. Environ. Sci. Technol. 2008, 42 (12), 4583-4588.

(28) Su, H. L.; Chou, C. C.; Hung, D. J.; Lin, S. H.; Pao, I. C.; Lin, J. H.; Huang, F. L.; Dong, R. X.; Lin, J. J. The disruption of bacterial membrane integrity through ROS generation induced by nanohybrids of silver and clay. Biomaterials 2009, 30 (30), 5979-5987.

(29) Kittler, S.; Greulich, C.; Diendorf, J.; Köller, M.; Epple, M. Toxicity of silver nanoparticles increases during storage because of slow dissolution under release of silver ions. Chem. Mater. 2010, 22 (16), 4548-4554.

(30) Campbell, K. M.; Root, R.; O’Day, P. A.; Hering, J. G. A gel probe equilibrium sampler for measuring arsenic porewater profiles and sorption gradients in sediments: I. Laboratory development. Environ. Sci. Technol. 2008, 42 (2), 497-503.

(31) Farnsworth, C. E.; Hering, J. G. Hydrous manganese oxide doped gel probe sampler for measuring in situ reductive dissolution rates. 1. Laboratory development. Environ. Sci. Technol. 2010, 44 (1), 34-40.

(32) Kneebone, P. E.; O’Day, P. A.; Jones, N.; Hering, J. G. Deposition and fate of arsenic in iron- and arsenic-enriched reservoir sediments. Environ. Sci. Technol. 2002, 36 (3), 381-386.

(33) Ho, C. M.; Yau, S. K. W.; Lok, C. N.; So, M. H.; Che, C. M. Oxidative dissolution of silver nanoparticles by biologically relevant oxidants: A kinetic and mechanistic study. Chem.-Asian J. 2010, 5 (2), 285-293.

(34) Liu, J. Y.; Sonshine, D. A.; Shervani, S.; Hurt, R. H. Controlled release of biologically active silver from nanosilver surfaces. ACS Nano 2010, 4 (11), 6903-6913.

(35) Henglein, A. Colloidal silver nanoparticles: Photochemical preparation and interaction with $\mathrm{O}_{2}, \mathrm{CCl}_{4}$, and some metal ions. Chem. Mater. 1998, 10 (1), 444-450.

(36) Yang, X. Y.; Gondikas, A. P.; Marinakos, S. M.; Auffan, M.; Liu, J.; Hsu-Kim, H.; Meyer, J. N. Mechanism of silver nanoparticle toxicity is dependent on dissolved silver and surface coating in Caenorhabditis elegans. Environ. Sci. Technol. 2012, 46 (2), 1119-1127.

(37) Li, X.; Lenhart, J. J.; Walker, H. W. Aggregation kinetics and dissolution of coated silver nanoparticles. Langmuir 2012, 28 (2), 1095-1104. 